Research Article

\title{
Colorimetric Detection Based on Localized Surface Plasmon Resonance Optical Characteristics for Sensing of Mercury Using Green-Synthesized Silver Nanoparticles
}

\author{
Eman Alzahrani iD \\ Chemistry Department, Faculty of Science, Taif University, Taif, Saudi Arabia \\ Correspondence should be addressed to Eman Alzahrani; em-s-z@hotmail.com
}

Received 27 July 2019; Revised 23 September 2019; Accepted 17 October 2019; Published 11 January 2020

Academic Editor: Miren Lopez de Alda

Copyright (c) 2020 Eman Alzahrani. This is an open access article distributed under the Creative Commons Attribution License, which permits unrestricted use, distribution, and reproduction in any medium, provided the original work is properly cited.

\begin{abstract}
Development of selective colorimetric detectors that can use green-fabricated silver nanoparticles' (AgNPs) with localized surface plasmon resonances (LSPRs) to rapidly, simply, and selectively detect $\mathrm{Hg}$ (II) ions was undertaken in this study. Onion extract was used for synthesising photo-induced green crystalline silver nanoparticles (NPs). The formation of nanoparticles is enhanced when ultrasound irradiation is present; bioligands could serve as stabilizing and reducing agents. Different methods of measurement, including UV-Vis, TEM, SEM/EDAX, FT - IR, and XRD, are effective for characterization of nanoparticles. The spherical nature of green-fabricated AgNPs is confirmed by TEM. High-density, spherical, and uniformly formed silver nanoparticle shapes were found in silver nanoparticle SEM images. The arrangement of AgNPs in the form of face-centered cubic structures was confirmed by XRD patterns. The formation of impurity-free AgNPs was confirmed using the EDAX analysis results. $\mathrm{Hg}^{2+}$ with excellent sensitivity was sensitively and selectively detected by employing green-synthesized silver nanoparticles. The reduction of $\mathrm{Ag}$ (1) to $\mathrm{Ag}(0)$ was confirmed by a slight increase in $\mathrm{Hg}$ (II) concentration and progressive reduction of green-synthesized AgNPs, whose absorbance changed abruptly. The reduction of LSPRs by the phosphate buffer medium enables AgNPs to sensitively and selectively detect $\mathrm{Hg}^{2+}$ ions by providing good environment. Besides, a selective, sensitive, simple, and rapid method that is proposed for detecting $\mathrm{Hg}$ (II) ions in samples of water is presented in the study. Harmful mercury ions in real samples of water (tap and ground water) can colorimetrically and selectively be detected using the AgNPs. The results showed an RSD of below $6 \%$ and over $92 \%$ of good recovery.
\end{abstract}

\section{Introduction}

The ecological environment and human health are seriously threatened by toxicity associated with heavy-metal ion contamination [1-4]. Dye, coal, plastic, paper, and natural gas industries exemplify heavy metal pollution sources [5-7]. Because of its highly toxic compounds, mercury ions $\left(\mathrm{Hg}^{2+}\right)$ present a significant concern among numerous heavy metals. Even in low concentrations, intestines, stomach, kidney, heart, and brain can be spoilt by $\mathrm{Hg}^{2+}$, which is among the most stable inorganic form of solvated mercuric ions [8-10]. In view of this, close attention should be accorded to selective detection of low concentration mercuric ions in biological systems and waste water; additionally, all contaminated products should be examined to identity the quantity of $\mathrm{Hg}^{2+}$. Drinking water should have concentration limits of not more than $2 \mathrm{ppb}$ for mercury ions, as outlined in the Environmental Protection Agency (EPA) and World Health Organization (WHO) requirements $[11,12]$.

Mercury ion detection can be undertaken using classical methods. Nevertheless, tedious laboratory procedures and expensive instruments complicate the use of such methods. In view of this, there is an increasing need for developing $\mathrm{Hg}^{2+}$ ion sensors that could be considered convenient, straightforward, cost-effective, real time, and on-site. $\mathrm{Nu}$ merous $\mathrm{Hg}^{2+}$ ion detection systems, including nanostructures [13, 14], DNA [15], proteins [16], polymers [17-19], and organic compounds [20, 21], have been reported in the literature. Because of the sensitive reaction that 
metallic nanoparticles have towards the nanoparticle surface local environment, significant attention has recently focused on their chemical sensing applications. Moreover, monitoring is simplified because they exhibit strong absorption or scattering. Because of the unique optical and electronic properties of silver and gold nanoparticles (NPs), they have become suitable for detecting different analytes than other metallic nanoparticles [22, 23]. Development of numerous gold particle- (AuNP-) based colorimetric sensors for detecting $\mathrm{Hg}^{2+}$ ions has been undertaken. The area of silver nanoparticle- (AgNP-) based detection system [24, 25] has received less research attention.

Significant research attention in the development of mercury sensors has been accorded to AgNPs, particularly because of soft-soft chemistry involving sulfur with stabilizing ligands on AgNPs surfaces, thus changing the peak position and absorbance intensity, the presence of redox chemistry involving $\mathrm{AgNPs}\left(\mathrm{Ag}^{\circ}\right)$ and $\mathrm{Hg}^{2+}$ leading to formation of $\mathrm{Ag}-\mathrm{Hg}$ mixture through nanoparticle etching, high sensitivity of AgNPs localized surface plasmon resonances, and cost-effective synthesis [2]. Besides, a UV - Vis spectrophotometer containing specific optical properties and which use LSPRs within the visibility range of $350-800 \mathrm{~nm}$ can be used for easy monitoring of AgNPs [26-31]. Radiation chemical reductions [32], photo reduction within reverse micelles [33], and chemical stabilisation with reagents, including sodium borohydride, ascorbate, and sodium citrate [34-37] have been used for synthesizing silver nanoparticles. The aforementioned methods cannot be scaled upwards easily for large-scale nanoparticle fabrication and require toxic chemicals, energy, pressure, or temperature, as well as high costs [38]. Moreover, the use of silver nanoparticles could be limited by the absorption of toxic chemicals on silver nanoparticle surfaces [39]. Biological methods involve the use of fungus [40], enzymes [41], or microorganisms [42, 43]; nevertheless, such methods require special attention to be accorded for preparation of cultures and methods to isolate the fabricated silver nanoparticles [44, 45]. Fabrication of silver nanoparticle using green chemistry would present numerous benefits that include less energy consumption, easy scaling up for large-scale nanoparticle fabrication, high yields, low cost, eliminates the necessity for special preparation of cultures and method of isolation, and environmentally friendly [44, 46-50].

Notably, the use of green-fabricated silver nanoparticles as the colorimeter detector in determining $\mathrm{Hg}^{2+}$ ions within phosphate buffer media that suppresses strong interference effects from other ions has received little research attention; in view of this, this study sought to fabricate green AgNPs for sensitive and selective colorimetric $\mathrm{Hg}^{2+}$ sensing within phosphate buffer media that suppresses strong interference effects from other ions on the basis of LSPR with green silver nanoparticles acting as the case of the model. To prevent use of hazardous or toxic chemicals, an eco-friendly technique was used for fabricating Ag nanoparticles. Under ultrasonic irradiation, AgNPs were fabricated using extract of onion as the reducing reagent of silver nitrate salt $\left(\mathrm{AgNO}_{3}\right)$. Fourier transform-infrared spectroscopy (FT - IR), XRD analysis, EDAX/SEM analysis, TEM analysis, and UV-visible spectra analysis were used for characterising the materials prepared. On the basis of reduced surface plasmon resonance (SPR) through a UV - Vis spectrophotometer as well as change in visual colour from yellow to colourless, less than 2 minutes could be used for detecting $\mathrm{Hg}^{2+}$. Samples of real drinking water were used to perform experiments that had high selectivity to $\mathrm{Hg}^{2+}$ ions. Besides, evaluation of the detection method in terms of calibration properties was undertaken.

\section{Experimental}

2.1. Chemicals and Reagents. A grocery store in Saudi's city of Taif supplied fresh onions. All chemicals were analytically graded. Acros Organics (Loughborough, UK) supplied the analytical grades of silver nitrate $\left(\mathrm{AgNO}_{3}\right)(99.8 \%)$ and various metal salts $\left(\mathrm{MnCl}_{2}, \mathrm{HgCl}_{2}, \mathrm{CdCl}_{2}, \mathrm{ZnCl}_{2}, \mathrm{CuCl}_{2}\right.$, $\mathrm{NiCl}_{2}, \mathrm{CoCl}_{2}, \mathrm{SrCl}_{2}, \mathrm{BaCl}_{2}, \mathrm{CaCl}_{2}, \mathrm{KCl}, \mathrm{NaCl}, \mathrm{FeCl}_{3}, \mathrm{AlCl}_{3}$, and $\mathrm{CrCl}_{3}$ ) employed in the study; no further purification was done on all the aforementioned. The required quantity of salt was mixed in double-distilled water to prepare all metallic salt solutions that were used in the experiments. Moreover, $\mathrm{NaOH}, \mathrm{HCl}$, sodium metaborate, boric acid, $\mathrm{Na}_{2} \mathrm{HPO}_{4}$, and $\mathrm{NaH}_{2} \mathrm{PO}_{4}$ were used for preparing $0.1 \mathrm{M}$ buffer solution. No further purification was done to all the chemicals used in the experiment. Distilled water was used for preparing all solutions.

2.2. Instrumentation. Fisher Scientific Co. Ltd., from Shanghai, China, supplied the bath sonicator $(42 \mathrm{kHz}$, $100 \mathrm{~W})$. Cambridge Instruments from the United Kingdom supplied a scanning electron microscope (SEM). JEOL Ltd from Welwyn Garden City, UK, supplied the transmission electron microscopy (TEM) instrument. A JEOL JSM 6390 LA analytical device from Tokyo, Japan, was used for conducting the energy dispersive X-ray (EDAX) analysis. Thermo Scientific ${ }^{\mathrm{TM}}$ GENESYS 10S from Toronto, Canada, supplied the UV-Vis spectrophotometer. A Bruker diffractometer D8-ADVANCE alongside $\mathrm{CuK} \alpha 1$ radiation from Coventry, UK, was used for obtaining $\mathrm{X}$ - ray diffraction patterns. A PerkinElmer RXFT - IR $\times 2$ device alongside DRIFT attachment and diamond ATR supplied by PerkinElmer from Buckinghamshire, UK, was used for collecting the attenuated total reflectance (ATR) mode.

2.3. Fabrication of the Green Ag Nanoparticles. After top skin of the onion was peeled ( $20 \mathrm{gm})$ and each segment separated, it was placed in room temperatures for 2 days. Filtration was conducted to the new solution to obtain onion extract concoction that is pale white and transparent, whereas the pieces of solid onion were removed, and prepared onion extract was utilised for synthesizing Ag nanoparticles. The concoction of onion extract measuring $20 \mathrm{~mL}$ was combined with $\mathrm{AgNO}_{3}$ in distilled water $(15 \mathrm{mM})$ to create a total volume of $50 \mathrm{~mL}$ with a final $\mathrm{AgNO}_{3}$ concentration of $1 \mathrm{mM}$. The concoctions were placed in the 
ultrasonic for 50 minutes, which yielded a light-orange colour, an indication that silver nanoparticles had been formed. The concoction was allowed to stay for 3 hours, yielding a deep brown-yellow colour. For removal of excessive free extracts of onion from the concoction, a 15minute centrifugation was undertaken at $7,000 \mathrm{rpm}$ for dispersions of silver nanoparticles. Finally, double-distilled water used to wash the formed Ag nanoparticles. Overall, the brownish residue is spread within double-distilled water and utilised for additional experiments.

2.4. Characterisation of the Green-Fabricated AgNPs. An ultraviolet-visible spectrophotometer was used for monitoring the fabricated silver nanoparticle solution, whereas the silver nanoparticle formation and solution colour were observed using naked eyes. A UV - Vis spectrophotometer was used for measuring the absorbance for the $1 \mathrm{~mL}$ sample solution, which was compared against $1 \mathrm{~mL}$ distilled water as the blank in the range of $350-800 \mathrm{~nm}$ operated at $1 \mathrm{~nm}$ resolution.

TEM analysis was used for studying silver nanoparticle formation. Here, $5 \mu \mathrm{L}$ sample solutions were placed onto lacey carbon-coated copper grids with a diameter of $3 \mathrm{~mm}$. A Gatan Ultrascan 4000 digital camera connected to a JEOL 2010 transmission electron microscope running at $20 \mathrm{kV}$ was used to obtain TEM images.

SEM was used for classifying silver nanoparticles in terms of morphologies. In the high vacuum mode, $100 \mathrm{pA}$ of probe current alongside $20 \mathrm{kV}$ increasing voltage was used for obtaining images. A 15 -minute centrifugation at $1100 \mathrm{rpm}$ was used for separating fabricated silver nanoparticles. The fabricated silver nanoparticles' chemical composition was obtained using the energy dispersive X-ray (EDAX) analysis.

A FT-IR spectrophotometer with a wavenumber ranging from 4000 to $600 \mathrm{~cm}^{-1}$ and $4 \mathrm{~cm}^{-1}$ resolution accuracy was used for obtaining a FT - IR spectrum. A ratio of $1: 100$ was used for mixing $\mathrm{KBr}$ and the ground sample. Afterwards, clear thin pellets were made after pressing. Recording of the spectra was done in the mode of transmittance as the wavenumber function.

XRD alongside $\mathrm{Cu}$ Ka radiation $(=1.5405 \mathrm{~A})$ within the 2-theta $(2 \theta)$ range of $35^{\circ}-80^{\circ}$ was used for performing structural analysis and phase identification.

2.5. General Procedure for the Colorimetric Determination of $\mathrm{Hg}^{2+}$. Generally, the procedure for $\mathrm{Hg}^{2+}$ colorimetric determination involved triple dilution of double-distilled deionized water, which yielded a three-fold diluted concentration. The ability of metal ions to detect transitionmetal ions $\left(\mathrm{Cd}^{2+}, \mathrm{Co}^{2+}, \mathrm{Hg}^{2+}, \mathrm{Zn}^{2+}, \mathrm{Cu}^{2+}, \mathrm{Mn}^{2+}\right.$, and $\left.\mathrm{Ni}^{2+}\right)$, alkaline Earth $\left(\mathrm{Ba}^{2+}, \mathrm{Sr}^{2+}\right.$, and $\left.\mathrm{Ca}^{2+}\right)$, representative alkali $\left(\mathrm{K}^{+}\right.$and $\left.\mathrm{Na}^{+}\right)$, trivalent metal ions $\left(\mathrm{Fe}^{3+}, \mathrm{Al}^{3+}\right.$, and $\left.\mathrm{Cr}^{3+}\right)$, and green-synthesized silver nanoparticles of similar concentration $\left(10^{-3} \mathrm{~mol} \mathrm{~L}^{-1}\right.$ and $\left.1 \mathrm{~mL}\right)$, and conditions were investigated by adding $2 \mathrm{~mL}$ of three times diluted solution of freshly prepared silver nanoparticle solution and $0.1 \mathrm{M}$ buffer solution measuring $100 \mu \mathrm{L}$. Room temperature was used for monitoring the UV-vis absorption spectra changes and the assays. After 2 minutes of mixing, a digital camera was used for taking photographs.

Indeed, the linear correlation involving the unreacted silver nanoparticles after loading mercury ions followed by the conventional galvanic reaction and the measured intensity of absorption constitutes the premise for the quantitative feedback titration approach. For construction of the calibration curve $\left(A_{\text {str }} v s \mathrm{Hg}^{2+}\right.$ volume), the change in conventional absorbance strength at optimum absorption wavelength was measured in form of absorption ratio $A_{\text {str }}$ denoted by the following equation [51, 52]:

$$
A_{\text {str }}=\frac{\left(A^{\circ}-A_{\mathrm{o}}\right)}{A^{\circ}} \times 100,
$$

where $A^{\circ}$ and $A_{\infty}$ denote the maximum absorbance for the absorption band of LSPR (subscripts "“" and " $\infty$ " represent the blank colloidal suspension prior to injection of required analyte concentration, as well as at infinite duration).

2.6. Recovery Experiments. Finally, three separate concentrations of mercury ions spiked with tap and ground water samples were used for performing the recovery experiments. Afterwards, mercury ion concentration in samples was computed using the linear regression equation and the assay response against samples of spiked water. Accordingly, the formula below was used for computing the recovery values [53]:

$$
\text { recovery }(\%)=\frac{\text { calculated }\left[\mathrm{Hg}^{2+}\right]}{\text { added }\left[\mathrm{Hg}^{2+}\right]} \times 100 \text {. }
$$

\section{Results and Discussion}

3.1. Formation of Green AgNPs. For use in analytical applications, stable silver nanoparticles should be synthesized against the dilution, over ionic strength, different $\mathrm{pH}$ ranges, and long storage period $[28,48,52]$. In this study, wetchemical green synthesis was used for preparing the green silver nanoparticles because it constituted the most prevalent procedure for fabricating uniform nanoparticles with regulated sizes and strong silver nanoparticles alongside their colloidal dispersions in organic solvents or water [54-56]. The onion extract as an eco-friendly reducing reagent and nontoxic bioextract that reduced silver ions $\left(\mathrm{Ag}^{+}\right)$to colloidal silver nanoparticles $\left(\mathrm{Ag}^{\circ}\right)$ was used for performing the reduction under a sonication bath. In the current study, ultrasonic irradiation was employed at the expense of magnetic stirring as past study reported [51], a significant reduction of $\mathrm{Ag}^{+}$alongside a higher formation of silver nanoparticles when utilising sonication bath, an indication that the reaction rate could be enhanced through ultrasonic irradiation.

\subsection{Characterisation of the Green AgNPs}

3.2.1. Optical Studies. Visual observation for silver nanoparticle formation is facilitated when colour change follows 
the conversion of silver ions to silver nanoparticles. In view of this, silver nanoparticle formation was monitored by visually checking the colour changes, and when the colour of the solution does not change further, the reaction was halted [57-59]. There was a gradual change in reaction mixture's colour from colourless into brown in 50 minutes because of silver nanoparticle formation within the solution, as illustrated in Figure 1(a). This is because of excitation of surface plasmon vibrations in AgNPs [60].

The $\mathrm{AgNO}_{3}$ solution and the green-fabricated silver nanoparticles in terms of the UV - Vis spectra are illustrated in Figure 1(b). The results showed that the $\mathrm{AgNO}_{3}$ solution had no absorbance, while the silver nanoparticles had an absorbance peak. A narrow, symmetrically sharp, and single LSPR band contained the colloidal solution's absorption spectra. The silver nanoparticles had an optimum absorbance peak of $405 \mathrm{~nm}$, thus implying the presence of a slightblue change as opposed to the optimum absorbance of between 410 and $422 \mathrm{~nm}$ for silver nanoparticles [61-63]. Thus far, the change characterising silver nanoparticle bands lacks a general principle. Nevertheless, dielectric environment, shape, and size differences could be the cause of band shift [64-67]. The final conversion of $\mathrm{AgNO}_{3}$ solution into AgNPs reached $100 \%$ in 50 minutes since the maximum absorbance of the formed AgNPs were not increased. After one month, the fabricated silver nanoparticles remain unaffected, an indication of stability and uniform dispersal for green-fabricated silver nanoparticles within aqueous solution. Besides, the green-prepared silver nanoparticles could be preserved in form of lyophilized powder over a prolonged period without the LSPR property shifting [68].

3.2.2. Morphological Characterisation. In this study, TEM analysis that can account for fabricated nanoparticle size and morphology was used for characterising green-fabricated silver nanoparticles $[28,69,70]$. Different magnifications for green-fabricated silver nanoparticle TEM micrographs are illustrated in Figure 2. The findings showed that the silver nanoparticles were within the nanorange with spherical shape and with good dispersal and without aggregation. In addition, a thin capping material layer from onion extract on the surface of AgNPs was observed, which can help stabilize the AgNPs in the solution for long period [71].

The green silver nanoparticles suspended in sterilized distilled water were utilised for SEM analysis through fabrication of suspension drops onto clean electric stubs, and the water was left to evaporate completely. The silver nanoparticles' SEM image indicated uniformly shaped and spherical nanoparticle formation with onion extract synthesizing high-density silver nanoparticles, a further confirmation of existing monodispersed silver nanoparticles, as illustrated in Figure 3. The same result was obtained by Jae Song and Beom Kim [60].

3.2.3. EDAX Analysis. Quantitative and qualitative data for fabricated material elements could be given through EDAX analysis. In view of this, EDAX analysis was used for greenfabricated silver nanoparticles. The sample's elemental composition is shown by the EDAX spectrum in Figure 4. Due to surface plasmon resonance, an optical absorption peak at $3 \mathrm{keV}$, and peaks at between $2 \mathrm{keV}$ and $4 \mathrm{keV}$, associated with silver's properties lines $\mathrm{L}$ and $\mathrm{K}[60,72,73]$ was found. This showed the presence of silver in the nanostructure. In addition, other aspects could be seen on the left side of EDAX spectrum, that is, sodium $(\mathrm{Na})$ at $1.041 \mathrm{keV}$ and oxygen $(\mathrm{O})$ at $0.525 \mathrm{keV}$. The tested samples sodium and oxygen peaks appeared from the biomolecules, which are bound to silver nanoparticle surface, and created a thin capping material layer and had stability in solution because of capping materials on the nanoparticle surface. For other groups, a similar outcome was obtained [74, 75].

The quantitative analysis was conducted using the obtained EDAX spectrum. The results showed that oxygen and sodium contents were $35.93 \%$ and $23.98 \%$, whereas silver content was high at $40.09 \%$ within the samples examined. The EDAX analysis results revealed formation of pure silver nanoparticles.

3.2.4. XRD Analysis. X-ray diffraction was used for analyzing the crystallinity of synthesized silver nanoparticles. XRD diffraction peaks of $76^{\circ}, 64^{\circ}, 46^{\circ}$, and $38^{\circ}$ that corre-

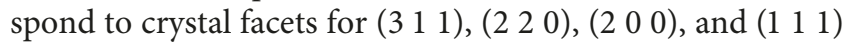
were found, as illustrated in Figure 5 . There is significant concurrence between face-centred cubic (FCC) structure $[76,77]$ Ag crystal and the peaks, an indication of crystalline silver presence in silver nanoparticles. Diffraction peaks that corresponded to the precursors $\left(\mathrm{AgNO}_{3}\right)$ or by-products (for instance, silver oxide) did not exist, thus confirming that in situ formation of metallic silver was only possible through reaction of onion extracts. The high crystallinity level for the synthesized silver nanoparticles is reflected by the peak intensity. Nevertheless, the breadth of diffraction peaks is an indication of small sizes of crystallite. This is consistent with the findings of Kumar et al. [78], Balavigneswaran et al [79], and Sheny et al. [80].

3.2.5. FT-IR Measurement. The green-fabricated silver nanoparticles' FT - IR spectrum after FT - IR spectroscopy was conducted, as illustrated in Figure 6. The $\mathrm{N}-\mathrm{H}$ stretching vibration, $\mathrm{O}-\mathrm{H}$ stretching vibration, and organic moiety such as carboxylic acid cause an intense broad band at $3400 \mathrm{~cm}^{-1}$. There is correspondence between polysaccharideoriented aromatic $\mathrm{C}-\mathrm{C}$ stretching vibrational modes and anionic carboxylate group and the absorption band at $1660 \mathrm{~cm}^{-1}$ [81]. This is in good agreement with the report done by Alzahrani et al. [52, 82]. The nanoparticles gain further stability when functionalization of silver nanoparticles that herbal extracts synthesized is undertaken using polysaccharides and aromatic compounds as documented within the FT-IR analysis. Silver ions within silver nanoparticles may be caused by aromatic compounds that exist within plant extracts.

3.3. Colorimetric Sensor. Metallic ion forms could accidentally be released when metals are extensively used in 


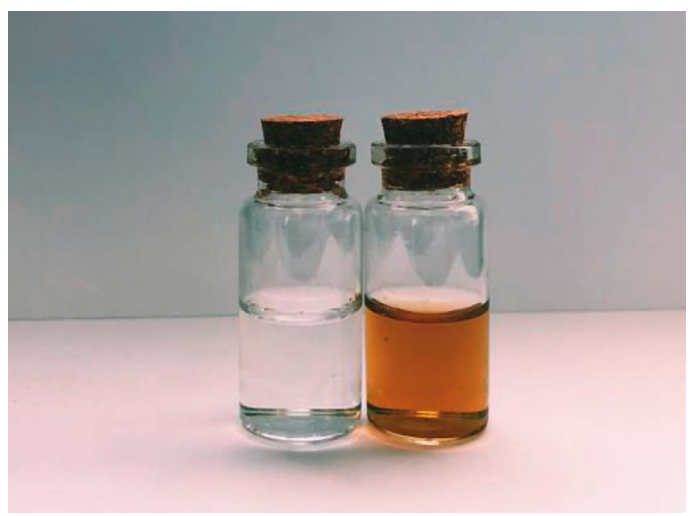

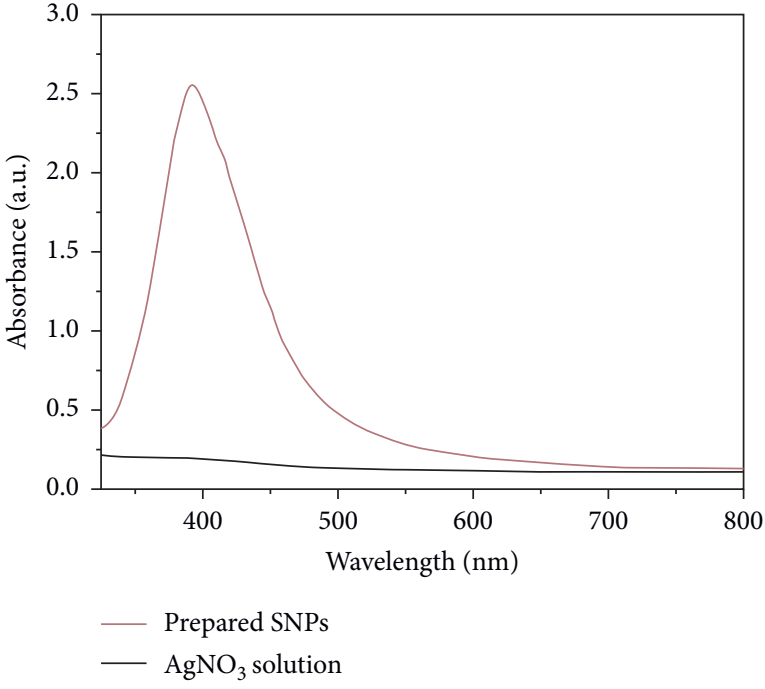

(b)

FIGURE 1: (a) The change in colour of the silver nitrate solution (transparent) after the reduction of silver ions and the formation of silver nanoparticles (dark brown) formed by onion extract; (b) comparison between the UV-visible absorption spectra of the green-prepared AgNPs and $\mathrm{AgNO}_{3}$ solution.

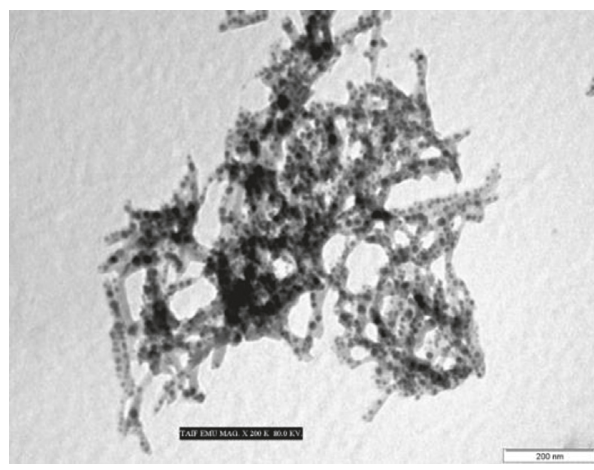

(a)

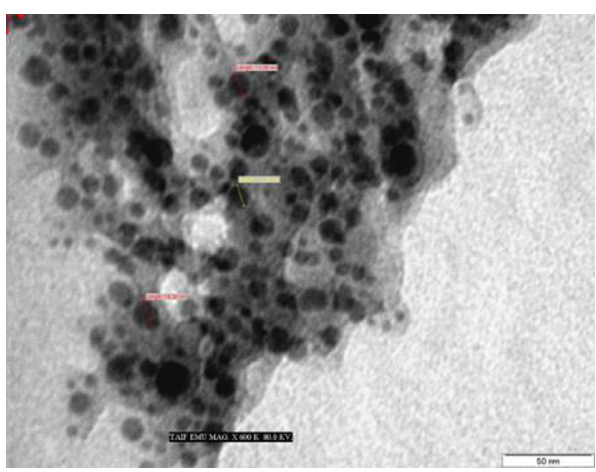

(b)

Figure 2: TEM images of the green-prepared AgNPs using different magnifications.

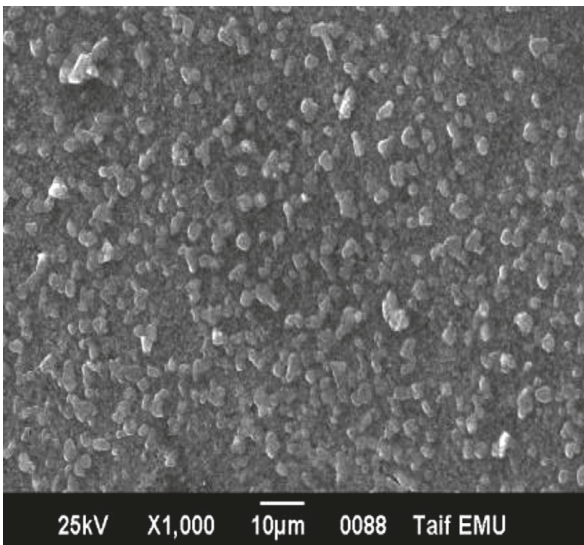

(a)

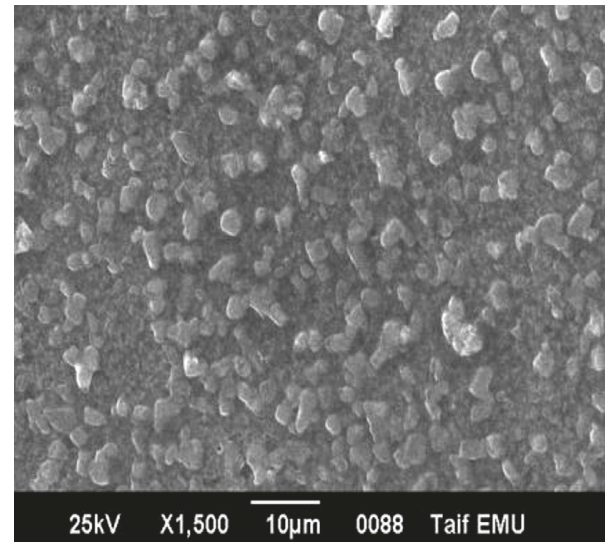

(b)

FIGURE 3: SEM images of the green-prepared AgNPs using different magnifications. 


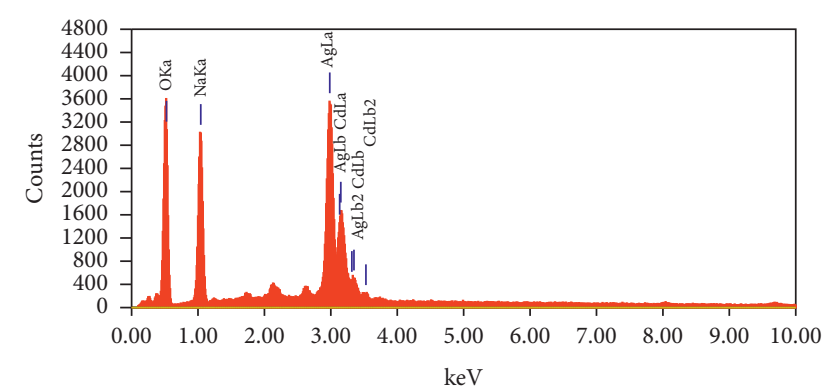

FIGURE 4: EDAX characteristic spectrum of the green-prepared AgNPs.

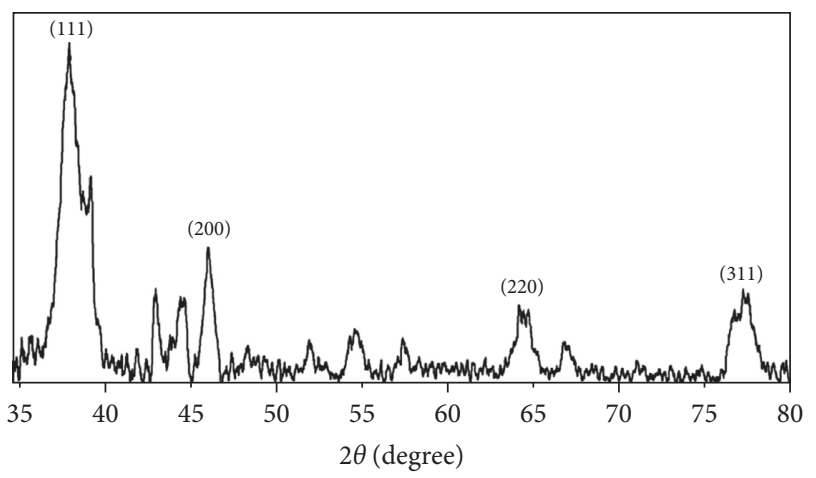

FIGURE 5: XRD pattern of the green-prepared AgNPs.

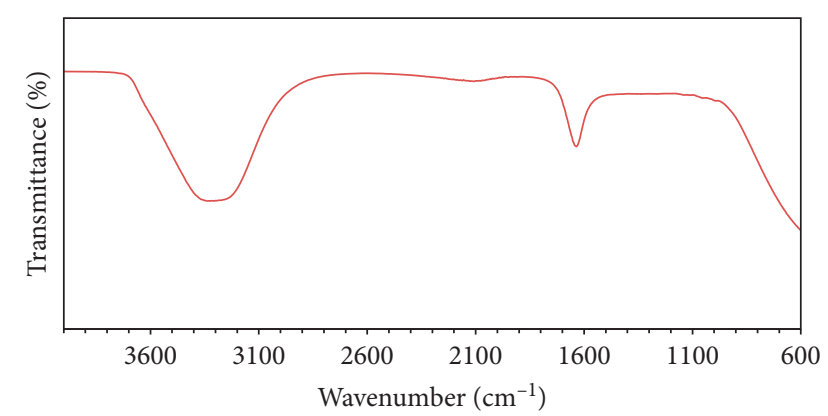

FIGURE 6: FT-IR transmittance spectrum of the green-prepared AgNPs.

different fields [83]. Water bodies and the environment face pollution from such metal ions. Owing to its existence in different forms including organic, inorganic, and elemental, mercury is regarded as the most toxic of all listed pollutants [84]. Conventional systems of detecting metal ions could be considered labour intensive or expensive [85]. The silver nanoparticles' SPR properties to detect transition metal ions, alkaline metal ions, alkali metal ions, and mercury ions were explored in this paper.

3.3.1. Detection of Alkali, Alkaline, and Trivalent Metal Ions. As Section 2.5 describes, $2 \mathrm{~mL}$ silver nanoparticle solution was added to $10^{-3} \mathrm{~mol} \mathrm{~L}^{-1}$ and $1 \mathrm{~mL}$ concentration containing salt stock solution to investigate how green-synthesized silver nanoparticles react to alkaline and alkali Earth metals. Afterwards, metal ion solutions were added creating an overall volume of $3 \mathrm{~mL}$ to investigate how different metal ions affected the LSPRs band intensity and the UV-Vis absorption spectra that corresponded were documented.

Absorption titrations were performed against alkaline metal ions such as $\mathrm{Sr}^{2+}, \mathrm{K}^{+}, \mathrm{Ca}^{2+}, \mathrm{Na}^{+}$, and $\mathrm{Ba}^{2+}$ ions and alkali metal to investigate the ability of green-fabricated silver nanoparticles to detect these ions. Based on the illustration in Figure 7(a), the silver nanoparticles' absorbance ratio and mixture colour were checked after the interaction of different alkaline metal ions and alkali metals. No change in silver nanoparticle colour was observed when alkaline metal ions or alkali metals were added to silver nanoparticles. The silver nanoparticle solution's $\mathrm{UV}-\mathrm{V}$ is absorbance after and before $1 \mathrm{~mL}$ of various alkaline metal ions or alkali metals was added and is illustrated in Figure 7(b). A change in spectrum was not observed for alkaline metal ions or alkali metals, and the optimum absorption wavelength of silver nanoparticles was found to be about $405 \mathrm{~nm}$. Changes in colour and LSPR absorption were not observed.

The colorimetric reaction of silver nanoparticles to different alkaline metal ions and alkali metals is illustrated in Figure 7(c). The detector's selectivity for these metal ions with green-fabricated silver nanoparticles was not observed. The same result was obtained when trivalent metal ions $\left(\mathrm{Fe}^{3+}, \mathrm{Al}^{3+}\right.$, and $\left.\mathrm{Cr}^{3+}\right)$ was used to check the ability of the green-fabricated silver nanoparticles to detect these metal ions (Figure 8).

3.3.2. Detection of Transition Metal Ions. The study investigated how silver nanoparticle solution was affected by transition metal ions. This was undertaken by examining various heavy metals including $\mathrm{Zn}^{2+}, \mathrm{Hg}^{2+}, \mathrm{Co}^{2+}, \mathrm{Cd}^{2+}$, $\mathrm{Cu}^{2+}, \mathrm{Ni}^{2+}$, and $\mathrm{Mn}^{2+}$ ions. Unlike other metals, there was a significant colour change in silver nanoparticles for transition metal ions after mercury ions were added, as illustrated in Figure 9(a). The results showed that when mercury ions were added to glass tubes that contained freshly prepared silver nanoparticle solution, there was a colour change for silver nanoparticle solution from brown to transparent; however, for transition heavy metals, there was no change after the silver nanoparticle solution was added, which implies the absence of effect on silver nanoparticle colour. In addition, it was found that the assay method has high specificity and selectivity toward mercury ions and alkaline metal, alkali metal, and other transition metal ions in similar conditions do not experience silver nanoparticle sensitivity.

The silver nanoparticles' UV-Vis absorbance after and before addition of $1 \mathrm{~mL}$ of various transition metal ions is illustrated in Figure 9(b). Unlike mercury ions that caused a change in spectrum, the silver nanoparticle colour and LSPR band did not experience any effect; in addition, the maximum wavelength had decreased absorbance, and there was apparition for new LSPR bands at longer UV-Vis spectra wavelength. The optical spectroscopic signatures for closedshell $d 10$ configuration $\mathrm{Hg}^{2+}$ do not exist [66]. After mercury was added to silver nanoparticles, solution colour changed to 

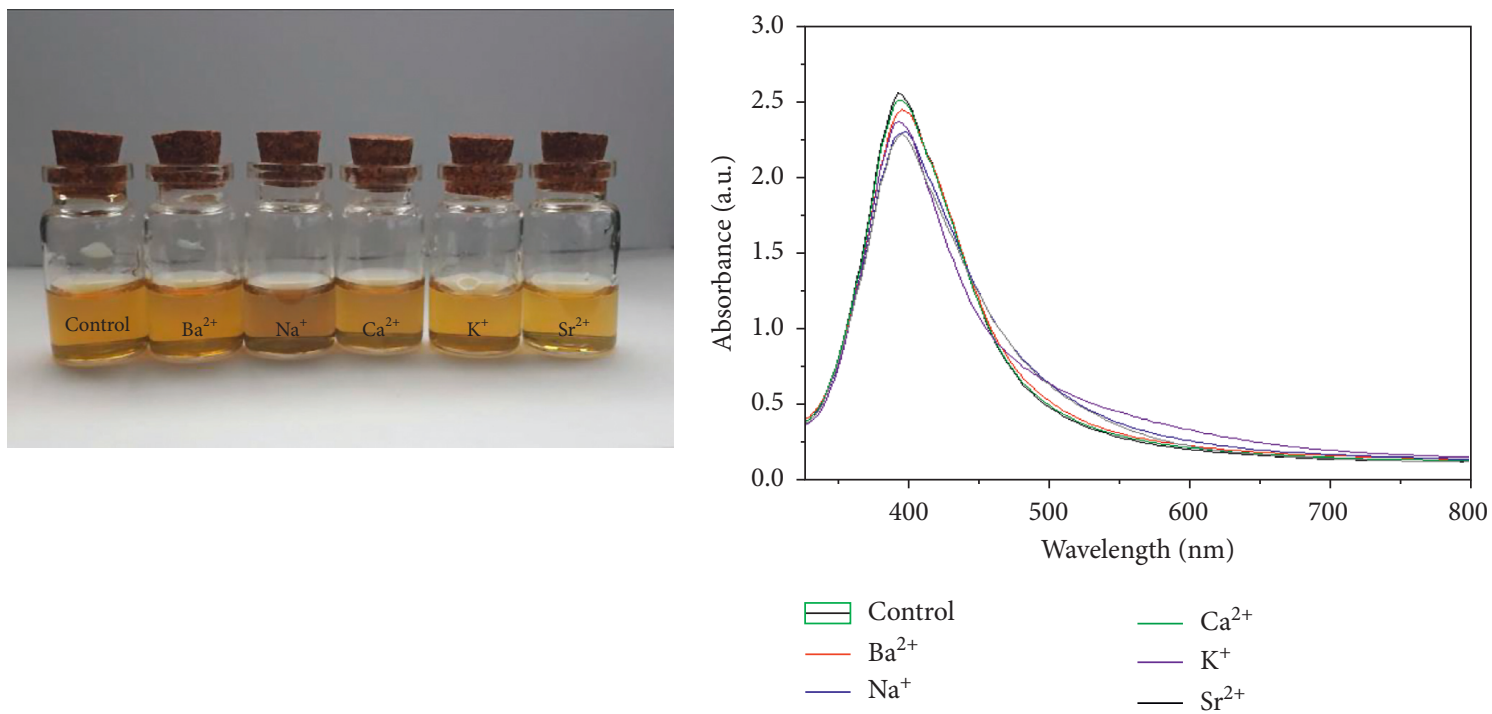

(a)

(b)

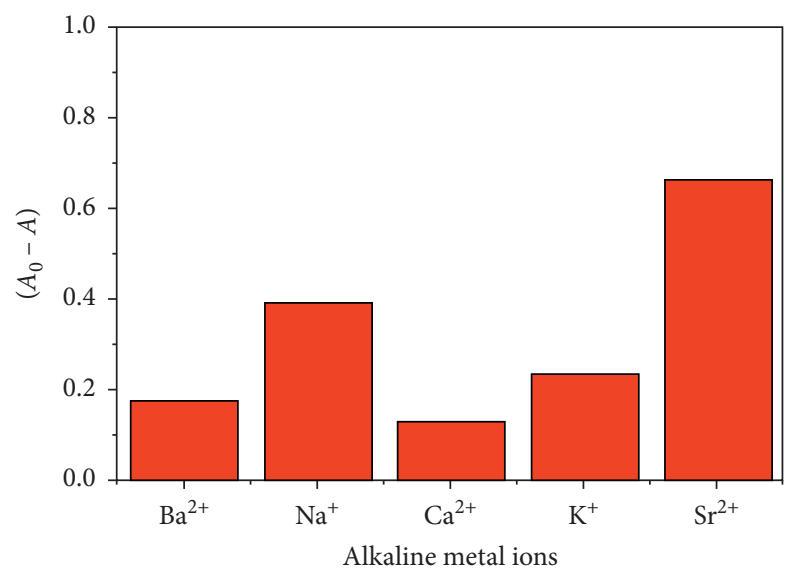

(c)

Figure 7: (a) Photo of the green-synthesized AgNPs solution towards various alkali and alkaline metal ions, (b) UV-Vis absorbance of the AgNPs before and after adding $1 \mathrm{~mL}$ of different alkali and alkaline metal ions, and (c) absorption ratio $(\triangle A)$ of AgNPs with different metal ions.

colourless and the silver nanoparticles did not have the LSPR band.

To further study the selective nature of silver nanoparticles towards different metal ions, the silver nanoparticle solution's absorbance was plotted with all transition metal ions. The selective nature of the optimized mercury ion sensor was examined by comparing solutions of other metallic ions against the silver nanoparticle absorbance ratio $\Delta A$. The silver nanoparticles $\Delta A$ intensity ratios of different metal ions clearly showed selectivity for mercury II ions, as illustrated in Figure 9(c). All the observations and results obtained indicate that aggregates of silver nanoparticles whose colour was transparent accounted for a significant ratio, whereas good dispersal of silver nanoparticles was demonstrated by a lower ratio [86]. By comparing Figures 7 (c) and 8 (c) with Figure $9(\mathrm{c})$, it is obvious that the absorption ratio ( $\triangle A$ of the green-fabricated silver nanoparticles with different metals (alkali, alkaline, trivalent, and transition metal ions) was less than 1.0 a.u. except for mercury, which was more than 2.5 a.u. These findings showed that silver nanoparticles had a reactive selectivity towards mercury II ions, as the dramatic absorbance ratio increased.

3.3.3. Investigation of Different Volumes of Mercury Ions. To examine the sensitive nature of the method and the minimum detectable mercury II ion within aqueous solutions by monitoring the values of UV-Vis absorbance and the system's colour change, different volumes of mercury ions' aqueous solution were incorporated to $2 \mathrm{~mL}$ silver nanoparticle solution in room temperatures. UV-Vis spectra for the silver nanoparticle LSPR property was used to determine the mercury II ion detection limit. There was a change in colour from yellow, light yellow, and light salmon to clear/transparent after different volumes of mercury II solution was introduced incrementally from 0 to $1400 \mu \mathrm{L}$, as illustrated in the photograph for silver nanoparticle solution 

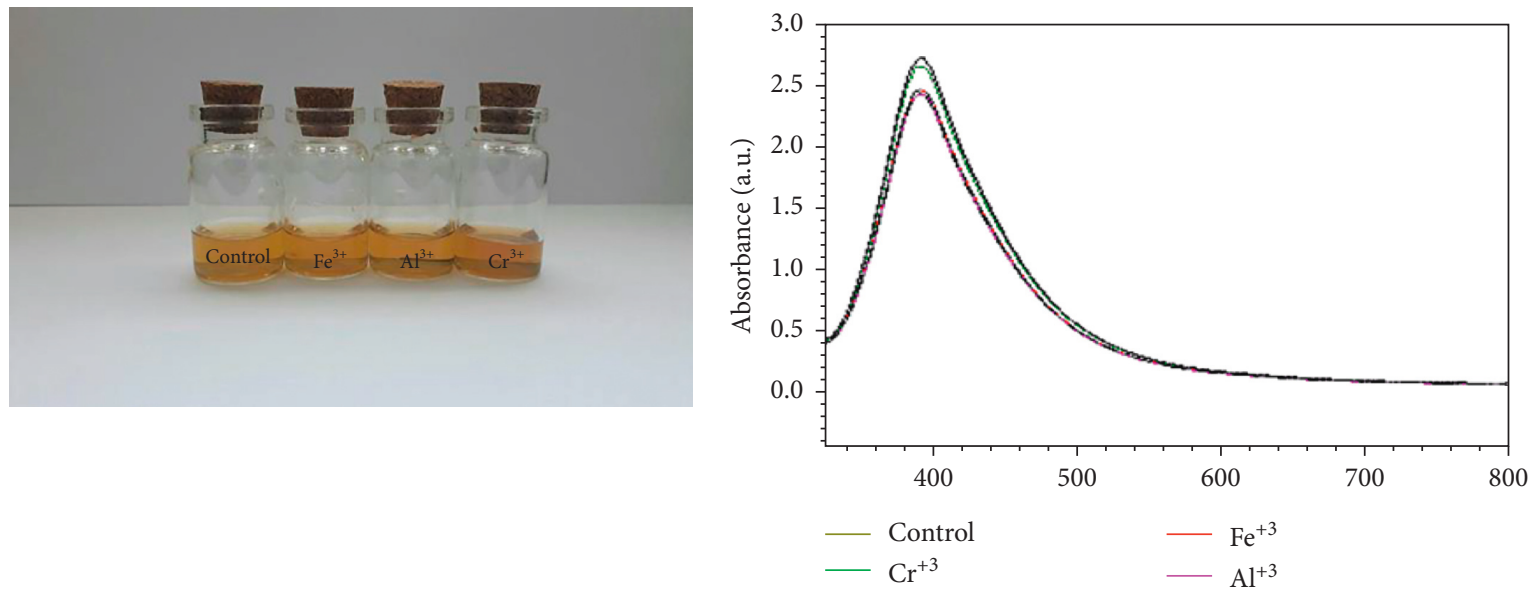

(a)

(b)

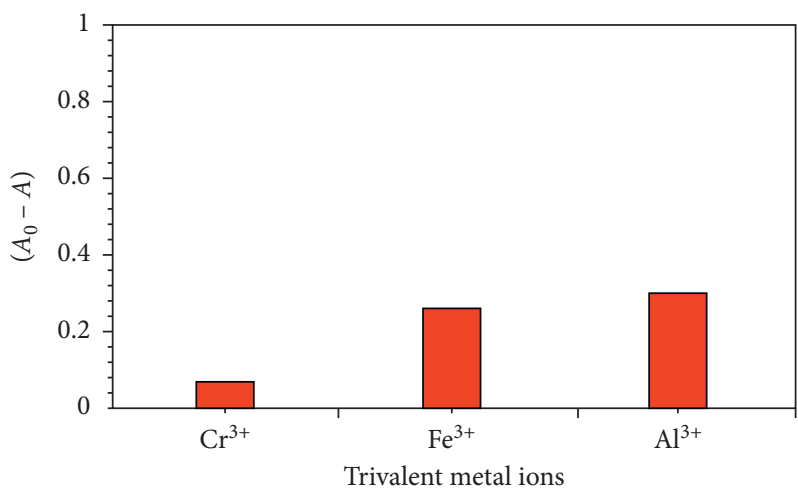

(c)

Figure 8: (a) Photo of the green-synthesized AgNPs solution towards various trivalent metal ions, (b) UV-Vis absorbance of the AgNPs before and after adding $1 \mathrm{~mL}$ of different trivalent metal ions, and (c) absorption ratio $(\triangle A)$ of AgNPs with various trivalent metal ions.

in Figure 10(a). Notably, the trend is significantly attributed to silver nanoparticle oxidation by mercury II ions caused by greater mercury/mercury ion potential $(0.851 \mathrm{~V})$, as opposed to silver/silver ions $(0.799 \mathrm{~V})[52,87]$. The reduction of silver nanoparticle LSPR band intensity was visible with mercury II ions. Because of this, a redox reaction will occur between mercury and silver ions. An amalgam of mercury and silver is formed when mercury II ions are reduced to mercury by the electrochemical reduction potential difference from oxidized silver nanoparticles [85].

Because of the colour change for silver nanoparticle solution, a UV-Vis spectrometer could be used for monitoring the change in LSPR optical properties. Figure 10(b) illustrates the correlation between mercury II ion and changes in the absorbance strength of LSPR. It could be inferred that the strength of LSPR absorbance changed significantly, and this was dependent on mercury II ion volume. Based on the figure, it could be stated that when mercury II ion increased, the absorbance peak of silver nanoparticles decreased. In addition, the absorption band of the surface plasmon might experience a slight change of blue shift when mercury II ions are increased. Findings have shown that reduction of mercury ions within aqueous silver solution from mercury layers around particles of silver could be undertaken radiolytically, followed by plasmon absorption band's blue shift and broadening [88]. Based on conducted experiments, metallic mercury was formed after silver nanoparticles reacted with the mercury II ion. The silver surface could offer the platform for strong bonding of newly generated mercury atoms, and this might be accounted for by slight-blue changes of the silver nanoparticles' LSPR band. The results could be considered the initial stage in the investigation of mercury ion detection. Indeed, a digestive technique can be used for transforming different forms of mercury such as $\mathrm{CH}_{3} \mathrm{HgCl}, \mathrm{CH}_{3} \mathrm{Hg}^{+}$, $\mathrm{HgO}, \mathrm{Hg}$, and $\mathrm{Hg}(\mathrm{OH})_{2}$ [89]. In view of this, the proposed study might provide a significant promise as the method for colorimetrically detecting overall forms of mercury.

Figure 10(c) illustrates the plot for colorimetric response $\left(A_{\text {str }}\right)$ against the mercury II ion volume through a construction of the absorption spectra that produced the calibration curve ( $A_{\text {str }}$ vs $\mathrm{Hg}^{2+}$ volume). A linear correlation $\left(y=0.0174 x+55.371, R^{2}=0.9582\right)$, between the mercury II ion volume and absorbance intensity, changes in the range of $0 \mu \mathrm{L}$ to $1400 \mu \mathrm{L}$ at $405 \mathrm{~nm}$. In view of this, it could be inferred that mercury II ion could be detected colorimetrically using green-synthesized silver nanoparticles. Sakly et al. [53] fabricated AgNPs coated with carboxymethyl 

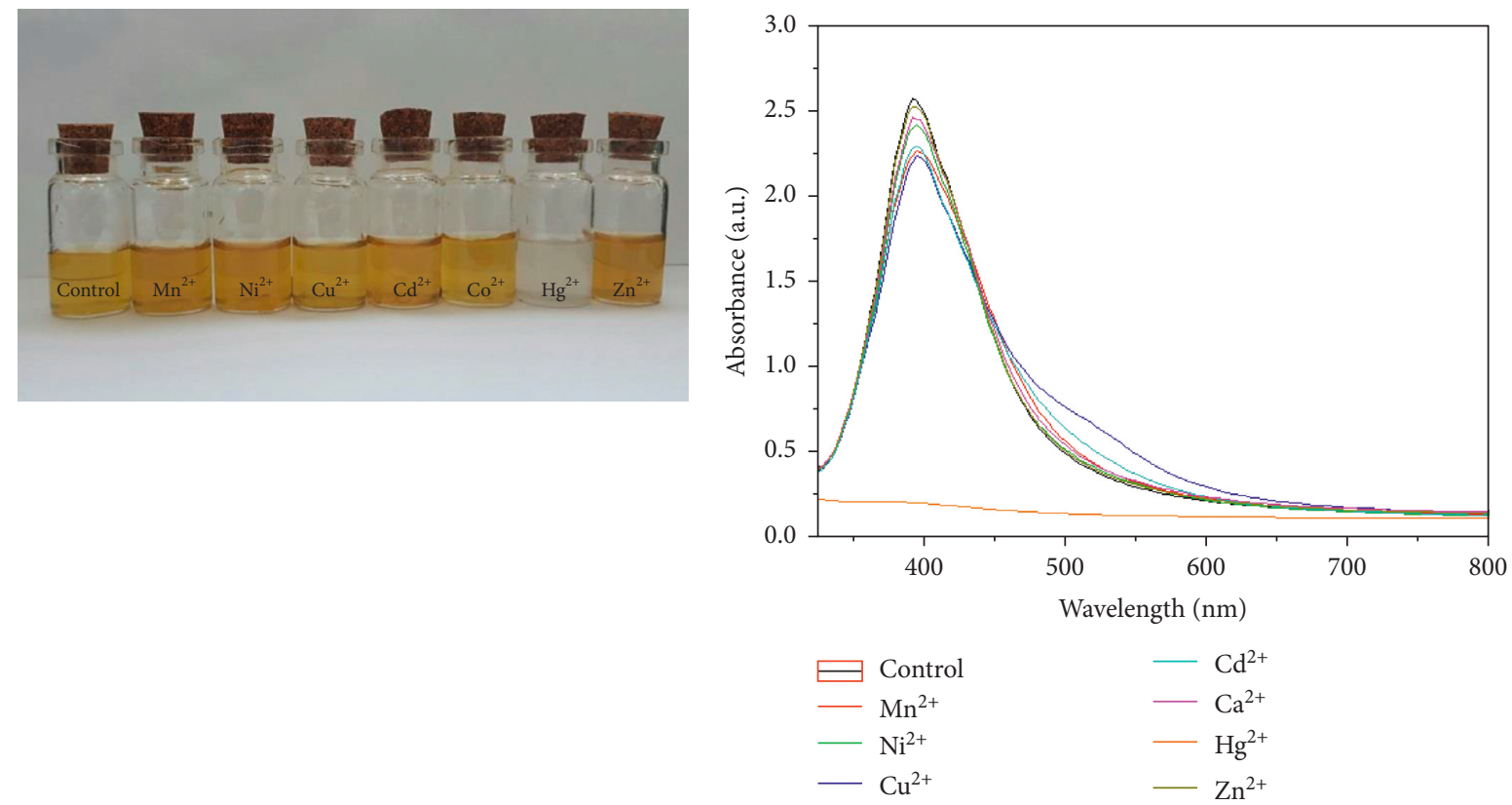

(a)

(b)

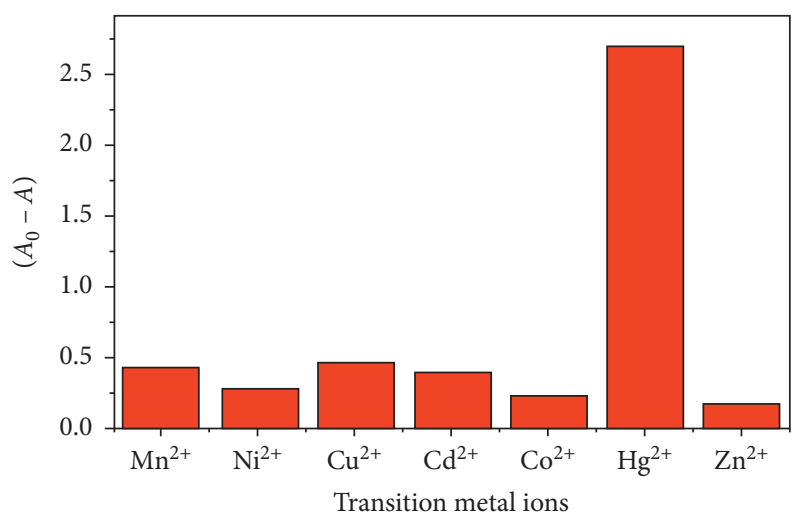

(c)

Figure 9: (a) Photo of the green-synthesized AgNPs solution towards various transition metal ions, (b) UV-Vis absorbance of the AgNPs before and after adding $1 \mathrm{~mL}$ of different transition metal ions, and (c) absorption ratio $(\triangle A)$ of AgNPs with various transition metal ions.

cellulose (CMC-capped AgNPs) from date palm tree for $\mathrm{Hg}^{2+}$ ion detection with $95 \%$ of good recovery, and RSD does not exceed $8 \%$. Although the recovery in this study is slightly low (92\%) compared with the previous study, the detection method was fast, simple, and selective colorimetric assay for $\mathrm{Hg}$ (II) ions. In addition, the procedure for fabrication of green AgNPs using onion extract was simple and fast.

After addition of mercury II ions, TEM analysis was used for examining the fabricated silver nanoparticles. Contrary to the results in Figures 2 and 11 showed that the introduction of mercury II ions completely changed the silver nanoparticles' morphology. The absorbance of the LSPR band had effective excitation, which was attributed to the dispersion media having dispersed and stable silver nanoparticles prior to addition of mercury II ions. In contrast, the introduction of mercury II ions to silver nanoparticles caused aggregation of nanoparticles through catalytic reactions between $\mathrm{Hg}^{2+}$ ions and silver nanoparticles; notably, the nanoparticle aggregation decreased the absorbance strength of the LSPR band. In addition, silver nanoparticle aggregation did not exist alongside other metal ions.

3.4. Practical Application. Notably, real samples of water were used at the micromolar level for evaluating the feasibility of the proposed detection method for mercury II ions. A specific volume obtained from the sample with drinking water was added to as-prepared colloidal solution that was spiked initially using $\mathrm{NaCl}$ aqueous solution (overall concentration $250 \mathrm{mM}$ ) before each sample was loaded with toxic ion. There was no detection of LSPR absorption spectra, regardless of the composition. Different mercury II ions mixed with spiked samples of drinking water were used for performing recovery experiments. Based on the results in Table 1, a relative standard deviation (RSD) of below $6 \%$ and 

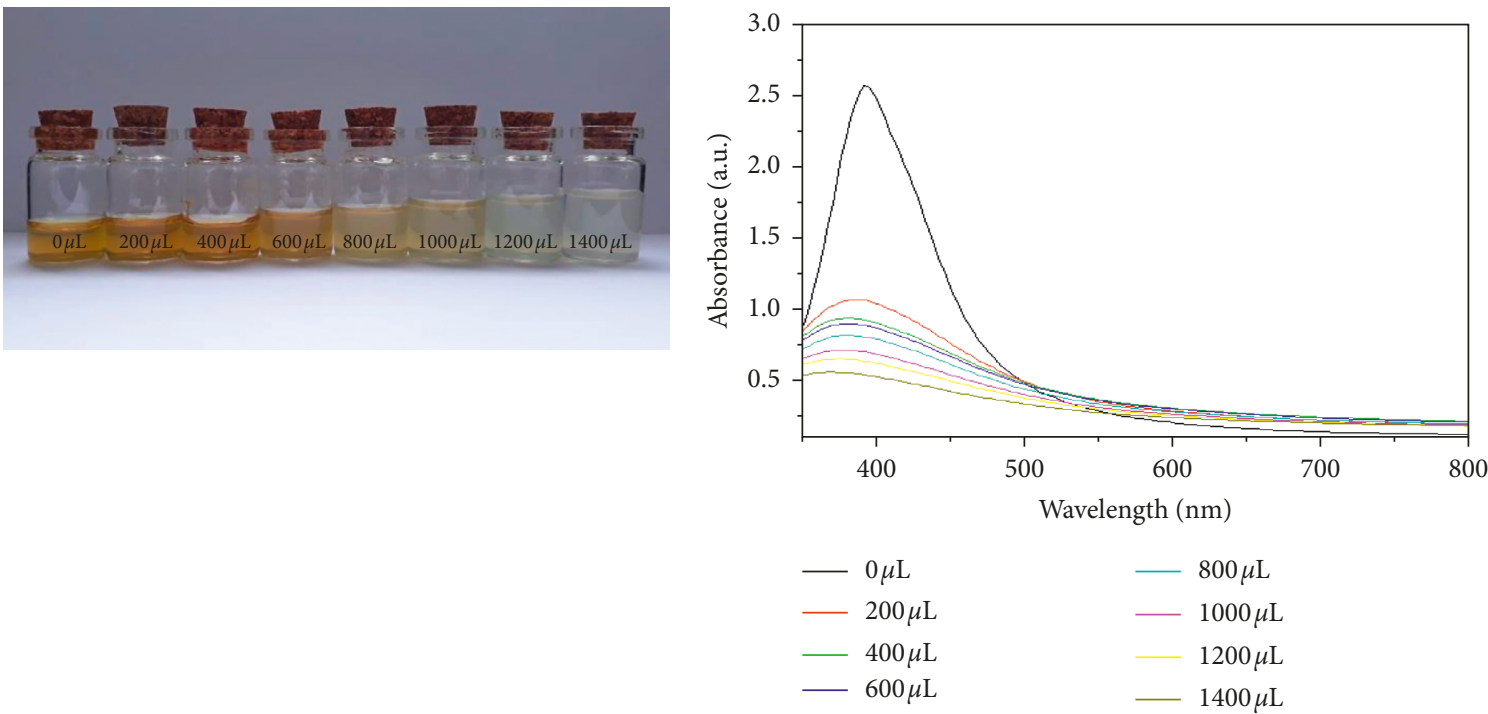

(a)

(b)

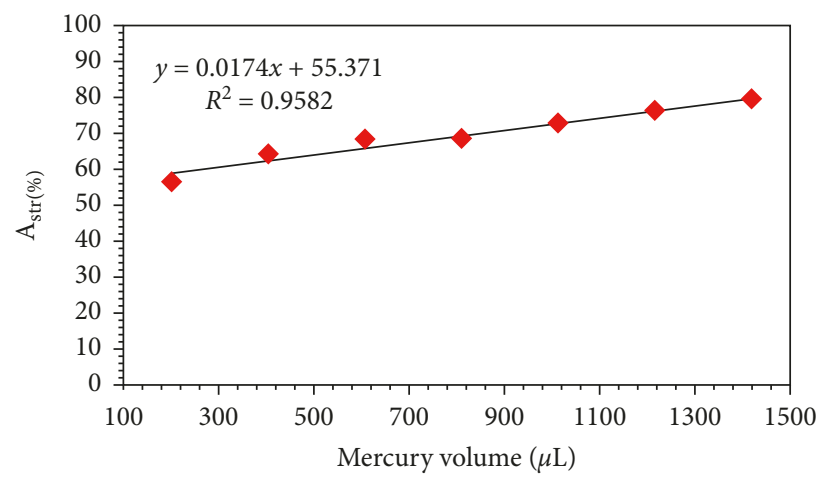

(c)

Figure 10: Colorimetric sensing of $\mathrm{Hg}^{2+}$ ion: (a) digital photograph, (b) UV-Vis absorption spectra of AgNPs before and after adding different volume of $\mathrm{HgCl}_{2}$ solution for 30 seconds, and (c) the function curve of the absorbance value versus the volume of $\mathrm{Hg}^{2+}$ in the range of $200-1400 \mu \mathrm{L}$ at $\mathrm{pH} 7.2$.

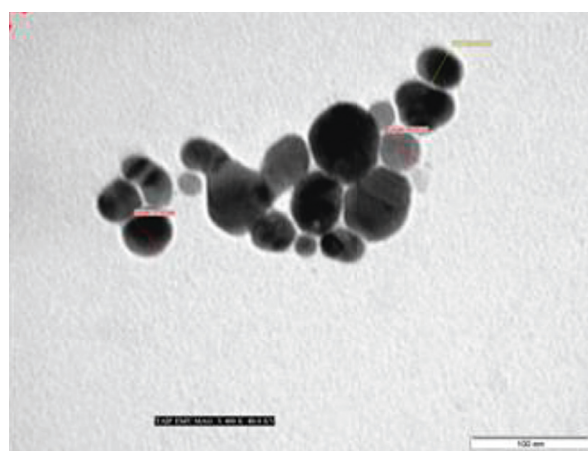

(a)

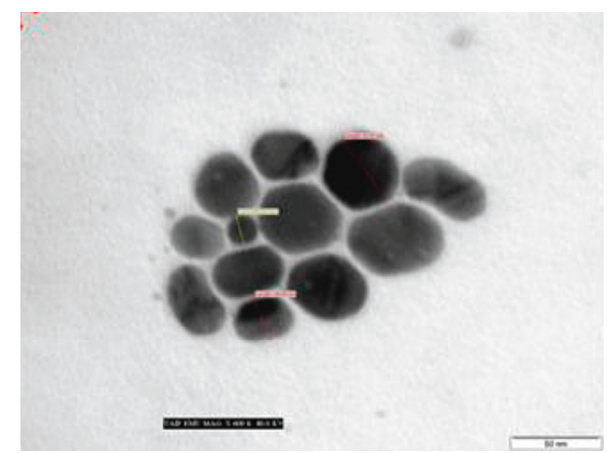

(b)

FIgURE 11: TEM micrographs of AgNPs after introducing $400 \mu \mathrm{L}$ of mercury (II) ion.

suitable recovery of over $92 \%$ were obtained. In addition, the table indicates that mercury II ion detection was not interfered with the composition of water samples. Besides, measurement repeatability was conducted on 3 colloidal solution replicates under similar experimental conditions. Because the RSD does surpass $6 \%$, the proposed assay could be considered reliable as confirmed by the results. Moreover, consistent with results, mercury poisoning could be 
TABLE 1: Estimation of $\mathrm{Hg}^{2+}$ concentration in real water samples using the fabricated SNPs as a sensor.

\begin{tabular}{lccc}
\hline Sample & Spiked $(\mu \mathrm{M})$ & Recovery $(\%)$ & RSD $(\%) n=3$ \\
\hline \multirow{3}{*}{ Ground water } & 300 & 97.8 & 5.97 \\
& 600 & 98.6 & 4.82 \\
& 900 & 93.5 & 3.84 \\
\hline \multirow{3}{*}{ Tap water } & 300 & 95.2 & 5.88 \\
& 600 & 97.4 & 4.76 \\
& 900 & 92.1 & 1.59 \\
\hline
\end{tabular}

$\mathrm{RSD}=$ relative standard deviation.

prevented by potentially applying the proposed colorimetric assay.

\section{Conclusion}

Overall, a selective, highly sensitive, rapid, ecofriendly, costeffective, label-free, and simple colorimetric assay to detect mercury II ions in samples of drinking water using greenprepared silver nanoparticles and onion extracts as the colorimetric probe, which allow mercury II ions to be detected in real time and rapidly, has been developed. Good stability and localized surface plasmons are exhibited by the green-synthesized silver nanoparticles. A similar chemistry is used for silver nanoparticle lowering LSPRs to etch out silver ions during mercury II ion sensing. Selective, rapid, cost-effective, and simple mercury II ion sensing within real water and biological samples in the future will benefit from this chemistry. Accordingly, plasmonic-assisted colorimetric assays for detecting mercury II ion will be enhanced when methodologies are enriched, and new approaches were applied through successful and full implementation of the eco-friendly colorimetric assay. Currently, the focus is on developing highly sensitive and selective (up to picomolar or nanomolar concentration range) for detection of hazardous metal ions using silver nanoparticles stabilized using onion extracts.

\section{Data Availability}

The data used to support the findings of this study are included within the article.

\section{Conflicts of Interest}

The author declares that there are no conflicts of interest.

\section{References}

[1] S. Mishra, R. N. Bharagava, N. More et al., "Heavy metal contamination: an alarming threat to environment and human health," in Environmental Biotechnology: For Sustainable Future, pp. 103-125, Springer, Singapore, 2019.

[2] J. Zhang, X. Sun, and J. Wu, "Heavy metal ion detection platforms based on a glutathione probe: a mini review," Applied Sciences, vol. 9, no. 3, pp. 489-507, 2019.

[3] P. Saha and B. Paul, "Assessment of heavy metal toxicity related with human health risk in the surface water of an industrialized area by a novel technique," Human and
Ecological Risk Assessment: an International Journal, vol. 25, no. 4, pp. 966-987, 2018.

[4] H. Eijsackers, A. Reinecke, S. Reinecke, and M. Maboeta, "Heavy metal threats to plants and soil life in southern Africa: present knowledge and consequences for ecological risk assessment," Reviews of Environmental Contamination and Toxicology, vol. 249, pp. 29-70, 2019.

[5] P. C. Nagajyoti, K. D. Lee, and T. V. M. Sreekanth, "Heavy metals, occurrence and toxicity for plants: a review," Environmental Chemistry Letters, vol. 8, no. 3, pp. 199-216, 2010.

[6] U. Förstner and G. T. Wittmann, Metal Pollution in the Aquatic Environment, Springer Science \& Business Media, Berlin, Germany, 2012.

[7] J. W. Moore and S. Ramamoorthy, Heavy Metals in Natural Waters: Applied Monitoring and Impact Assessment, Springer Science \& Business Media, Berlin, Germany, 2012.

[8] S. Ghosh, S. Maji, and A. Mondal, "Study of selective sensing of $\mathrm{Hg}^{2+}$ ions by green synthesized silver nanoparticles suppressing the effect of $\mathrm{Fe}^{3+}$ ions," Colloids and Surfaces A: Physicochemical and Engineering Aspects, vol. 555, pp. 324331, 2018.

[9] T. W. Clarkson, L. Magos, and G. J. Myers, "The toxicology of mercury-current exposures and clinical manifestations," New England Journal of Medicine, vol. 349, no. 18, pp. 1731-1737, 2003.

[10] Y. Wang, F. Yang, and X. Yang, "Colorimetric biosensing of mercury(II) ion using unmodified gold nanoparticle probes and thrombin-binding aptamer," Biosensors and Bioelectronics, vol. 25, no. 8, pp. 1994-1998, 2010.

[11] M. Update, "Impact on fish advisories," Office of Water, Washington, DC, USA, EPA fact sheet EPA-823-F-01-011, 2001.

[12] F. Edition, "Guidelines for drinking-water quality," WHO Chronicle, vol. 38, no. 4, pp. 104-108, 2011.

[13] M. Rex, F. E. Hernandez, and A. D. Campiglia, "Pushing the limits of mercury sensors with gold nanorods," Analytical Chemistry, vol. 78, no. 2, pp. 445-451, 2006.

[14] C.-C. Huang and H.-T. Chang, "Selective gold-nanoparticlebased "turn-on" fluorescent sensors for detection of mercury(II) in aqueous solution," Analytical Chemistry, vol. 78, no. 24, pp. 8332-8338, 2006.

[15] J. Liu and Y. Lu, "Rational design of "turn-on" Allosteric DNAzyme catalytic beacons for aqueous mercury ions with ultrahigh sensitivity and selectivity," Angewandte Chemie International Edition, vol. 46, no. 40, pp. 7587-7590, 2007.

[16] S. V. Wegner, A. Okesli, P. Chen, and C. He, "Design of an emission ratiometric biosensor from MerR family proteins: a sensitive and selective sensor for $\mathrm{Hg}^{2+}$," Journal of the American Chemical Society, vol. 129, no. 12, pp. 3474-3475, 2007.

[17] Y. Zhao and Z. Zhong, "Tuning the sensitivity of a foldamerbased mercury sensor by its folding energy," Journal of the American Chemical Society, vol. 128, no. 31, pp. 9988-9989, 2006.

[18] X. Liu, Y. Tang, L. Wang et al., "Optical detection of mercury(II) in aqueous solutions by using conjugated polymers and label-free oligonucleotides," Advanced Materials, vol. 19, no. 11, pp. 1471-1474, 2007.

[19] I.-B. Kim and U. H. F. Bunz, "Modulating the sensory response of a conjugated polymer by proteins: an agglutination assay for mercury ions in water," Journal of the American Chemical Society, vol. 128, no. 9, pp. 2818-2819, 2006.

[20] S. Yoon, A. E. Albers, A. P. Wong, and C. J. Chang, "Screening mercury levels in fish with a selective fluorescent 
chemosensor," Journal of the American Chemical Society, vol. 127, no. 46, pp. 16030-16031, 2005.

[21] C.-K. Chiang, C.-C. Huang, C.-W. Liu, and H.-T. Chang, "Oligonucleotide-based fluorescence probe for sensitive and selective detection of mercury(II) in aqueous solution," $A n$ alytical Chemistry, vol. 80, no. 10, pp. 3716-3721, 2008.

[22] G. A. Messina, M. Regiart, S. V. Pereira et al., "Nanomaterials in the development of biosensor and application in the determination of pollutants in water," in Advanced Research in Nanosciences for Water Technology, pp. 195-215, Springer, Berlin, Germany, 2019.

[23] L. Tamayo, H. Palza, J. Bejarano, and P. A. Zapata, "Polymer composites with metal nanoparticles: synthesis, properties, and applications," Polymer Composites with Functionalized Nanoparticles, pp. 249-286, Elsevier, Amsterdam, Netherlands, 2019.

[24] C. Sönnichsen, B. M. Reinhard, J. Liphardt, and A. P. Alivisatos, "A molecular ruler based on plasmon coupling of single gold and silver nanoparticles," Nature Biotechnology, vol. 23, no. 6, pp. 741-745, 2005.

[25] Y. Wang, F. Yang, and X. Yang, "Colorimetric detection of mercury(II) ion using unmodified silver nanoparticles and mercury-specific oligonucleotides," ACS Applied Materials \& Interfaces, vol. 2, no. 2, pp. 339-342, 2010.

[26] M. Willander, O. Nur, Y. E. Lozovik et al., "Solid and soft nanostructured materials: fundamentals and applications," Microelectronics Journal, vol. 36, no. 11, pp. 940-949, 2005.

[27] Y. Kobayashi, H. Katakami, E. Mine, D. Nagao, M. Konno, and L. M. Liz-Marzán, "Silica coating of silver nanoparticles using a modified Stöber method," Journal of Colloid and Interface Science, vol. 283, no. 2, pp. 392-396, 2005.

[28] E. Alzahrani, "Eco-friendly production of silver nanoparticles from peel of tangerine for degradation of dye," World Journal of Nano Science and Engineering, vol. 5, no. 1, pp. 10-16, 2015.

[29] D. Mandal, S. Mishra, and R. K. Singh, "Green synthesized nanoparticles as potential nanosensors," in Environmental, Chemical and Medical Sensors, pp. 137-164, Springer, Berlin, Germany, 2018.

[30] L. Chen, Y. Wang, X. Fu, and L. Chen, Novel Optical Nanoprobes for Chemical and Biological Analysis, Springer, Berlin, Germany, 2014.

[31] Y. Li, F. Zheng, Z. Li, and J. Laven, "Silver nanoparticles prepared by using poly(2-acrylamido-2-methylpropane sulphonic acid) as a surfactant," Micro \& Nano Letters, vol. 9, no. 10, pp. 750-752, 2014.

[32] A. Henglein, "Physicochemical properties of small metal particles in solution: "microelectrode" reactions, chemisorption, composite metal particles, and the atom-to-metal transition," The Journal of Physical Chemistry, vol. 97, no. 21, pp. 5457-5471, 1993.

[33] Y.-P. Sun, P. Atorngitjawat, and M. J. Meziani, "Preparation of silver nanoparticles via rapid expansion of water in carbon dioxide microemulsion into reductant solution," Langmuir, vol. 17, no. 19, pp. 5707-5710, 2001.

[34] I. Pastoriza-Santos and L. M. Liz-Marzán, "formation and stabilization of silver nanoparticles through reduction by $N, N$-dimethylformamide," Langmuir, vol. 15 , no. 4, pp. 948-951, 1999.

[35] S. Iravani, H. Korbekandi, S. Mirmohammadi, and B. Zolfaghari, "Synthesis of silver nanoparticles: chemical, physical and biological methods," Research in Pharmaceutical Sciences, vol. 9, no. 6, pp. 385-406, 2014.
[36] T. Ahmad, I. A. Wani, and S. Khatoon, "Controlling the size and morphology of silver nanoparticles: role of chemical routes," Nanotech, vol. 1, pp. 292-298, 2011.

[37] X. He, A. Lu, J. Cheng et al., "Overview of the application of flow microreactors in the synthesis of silver nanomaterials," Nano, vol. 12, no. 11, p. 1730002, 2017.

[38] S. Ponarulselvam, C. Panneerselvam, K. Murugan, N. Aarthi, K. Kalimuthu, and S. Thangamani, "Synthesis of silver nanoparticles using leaves of Catharanthus roseus Linn. G. Don and their antiplasmodial activities," Asian Pacific Journal of Tropical Biomedicine, vol. 2, no. 7, pp. 574-580, 2012.

[39] P. Liu, B.-C. Yang, G. Liu et al., "Improving power conversion efficiency of perovskite solar cells by cooperative LSPR of gold-silver dual nanoparticles," Chinese Physics B, vol. 26, no. 5, Article ID 058401, 2017.

[40] X. Zhang, X. He, K. Wang, and X. Yang, "Different active biomolecules involved in biosynthesis of gold nanoparticles by three fungus species," Journal of Biomedical Nanotechnology, vol. 7, no. 2, pp. 245-254, 2011.

[41] I. Willner, R. Baron, and B. Willner, "Growing metal nanoparticles by enzymes," Advanced Materials, vol. 18, no. 9, pp. 1109-1120, 2006.

[42] S. Prabhu and E. K. Poulose, "Silver nanoparticles: mechanism of antimicrobial action, synthesis, medical applications, and toxicity effects," International Nano Letters, vol. 2, no. 1, pp. 1-10, 2012.

[43] Y. Konishi, K. Ohno, N. Saitoh et al., "Bioreductive deposition of platinum nanoparticles on the bacterium Shewanella algae," Journal of Biotechnology, vol. 128, no. 3, pp. 648-653, 2007.

[44] A. Saxena, R. Tripathi, and R. Singh, "Biological synthesis of silver nanoparticles by using onion (Allium cepa) extract and their antibacterial activity," Digest Journal of Nanomaterials and Biostructures, vol. 5, no. 2, pp. 427-432, 2010.

[45] D. Jain, H. K. Daima, S. Kachhwaha, and S. Kothari, "Synthesis of plant-mediated silver nanoparticles using papaya fruit extract and evaluation of their anti microbial activities," Digest Journal of Nanomaterials and Biostructures, vol. 4, no. 3, pp. 557-563, 2009.

[46] S. K. Srikar, D. D. Giri, D. B. Pal, P. K. Mishra, and S. N. Upadhyay, "Green synthesis of silver nanoparticles: a review," Green and Sustainable Chemistry, vol. 6, no. 1, pp. 34-56, 2016.

[47] S. Ahmed, M. Ahmad, B. L. Swami, and S. Ikram, "A review on plants extract mediated synthesis of silver nanoparticles for antimicrobial applications: a green expertise," Journal of Advanced Research, vol. 7, no. 1, pp. 17-28, 2016.

[48] E. Alzahrani and K. Welham, "Optimization preparation of the biosynthesis of silver nanoparticles using watermelon and study of itsantibacterial activity," International Journal of Basic and Applied Sciences, vol. 3, no. 4, pp. 392-400, 2014.

[49] N. Geetha, K. Harini, J. J. Showmya, and K. S. Priya, "Biofabrication of silver nanoparticles using leaf extract of Chromolaena odorata (L.) king and robinson," International Conference on Nuclear Energy, Environmental and Biological Sciences, vol. 8, pp. 56-59, 2012.

[50] L. Ma, W. Su, J.-X. Liu et al., "Optimization for extracellular biosynthesis of silver nanoparticles by Penicillium aculeatum Sul and their antimicrobial activity and cytotoxic effect compared with silver ions," Materials Science and Engineering: C, vol. 77, pp. 963-971, 2017.

[51] P. Vasileva, B. Donkova, I. Karadjova, and C. Dushkin, "Synthesis of starch-stabilized silver nanoparticles and their application as a surface plasmon resonance-based sensor of 
hydrogen peroxide," Colloids and Surfaces A: Physicochemical and Engineering Aspects, vol. 382, no. 1-3, pp. 203-210, 2011.

[52] E. Alzahrani, "Colorimetric detection based on localised surface plasmon resonance optical characteristics for the detection of hydrogen peroxide using acacia gum-stabilised silver nanoparticles," Analytical Chemistry Insights, vol. 12, pp. 1-10, 2017.

[53] N. Sakly, W. Marzouk, H. B. Ouada, and H. Majdoub, "Enhancing performances of colorimetric response of carboxymethylcellulose-stabilized silver nanoparticles: a fully eco-friendly assay for $\mathrm{Hg}^{2+}$ detection," Sensors and Actuators B: Chemical, vol. 253, pp. 918-927, 2017.

[54] B. Swain, C. Mishra, H. S. Hong, and S.-S. Cho, "Selective recovery of pure copper nanopowder from indium-tin-oxide etching wastewater by various wet chemical reduction process: understanding their chemistry and comparisons of sustainable valorization processes," Environmental Research, vol. 147, pp. 249-258, 2016.

[55] K. Rajan, I. Roppolo, A. Chiappone, S. Bocchini, D. Perrone, and A. Chiolerio, "Silver nanoparticle ink technology: state of the art," Nanotechnology, Science and Applications, vol. 9, pp. 1-13, 2016.

[56] T. Altantzis, Z. Yang, S. Bals, G. Van Tendeloo, and M.-P. Pileni, "Thermal stability of $\mathrm{CoAu}_{13}$ binary nanoparticle superlattices under the electron beam," Chemistry of Materials, vol. 28, no. 3, pp. 716-719, 2016.

[57] S. I. I. Abdel-Hafez, N. A. Nafady, I. R. Abdel-Rahim, A. M. Shaltout, and M. A. Mohamed, "Biogenesis and optimisation of silver nanoparticles by the endophytic fungus cladosporium sphaerospermum," International Journal of Nanomaterials and Chemistry, vol. 2, no. 1, pp. 11-19, 2016.

[58] P. Mosae Selvakumar, C. A. Antonyraj, R. Babu, A. Dakhsinamurthy, N. Manikandan, and A. Palanivel, "Green synthesis and antimicrobial activity of monodispersed silver nanoparticles synthesized using lemon extract," Synthesis and Reactivity in Inorganic, Metal-Organic, and NanoMetal Chemistry, vol. 46, no. 2, pp. 291-294, 2016.

[59] A. N. D. Krupa, M. E. A. Abigail, C. Santhosh, A. N. Grace, and R. Vimala, "Optimization of process parameters for the microbial synthesis of silver nanoparticles using 3-level BoxBehnken Design," Ecological Engineering, vol. 87, pp. 168-174, 2016.

[60] H. Bar, D. K. Bhui, G. P. Sahoo, P. Sarkar, S. P. De, and A. Misra, "Green synthesis of silver nanoparticles using latex of Jatropha curcas," Colloids and Surfaces A: Physicochemical and Engineering Aspects, vol. 339, no. 1-3, pp. 134-139, 2009.

[61] C. Y. Tai, Y.-H. Wang, and H.-S. Liu, "A green process for preparing silver nanoparticles using spinning disk reactor," AIChE Journal, vol. 54, no. 2, pp. 445-452, 2008.

[62] S. Chairam and E. Somsook, "Starch vermicelli template for synthesis of magnetic iron oxide nanoclusters," Journal of Magnetism and Magnetic Materials, vol. 320, no. 15, pp. 2039-2043, 2008.

[63] S. Chairam, C. Poolperm, and E. Somsook, "Starch vermicelli template-assisted synthesis of size/shape-controlled nanoparticles," Carbohydrate Polymers, vol. 75, no. 4, pp. 694-704, 2009.

[64] J. P. Wilcoxon and B. L. Abrams, "Synthesis, structure and properties of metal nanoclusters," Chemical Society Reviews, vol. 35, no. 11, pp. 1162-1194, 2006.

[65] K. L. Kelly, E. Coronado, L. L. Zhao, and G. C. Schatz, "The optical properties of metal nanoparticles: the influence of size, shape, and dielectric environment," The Journal of Physical Chemistry B, vol. 107, no. 3, pp. 668-677, 2003.
[66] K. Farhadi, M. Forough, R. Molaei, S. Hajizadeh, and A. Rafipour, "Highly selective $\mathrm{Hg}^{2+}$ colorimetric sensor using green synthesized and unmodified silver nanoparticles," Sensors and Actuators B: Chemical, vol. 161, no. 1, pp. 880$885,2012$.

[67] L. Guoliang, J. Lei, C. Liyuan, and P. Bing, "Preparation of nanosilver by using water-insoluble reducing agent o-phenylenediamine," Micro \& Nano Letters, vol. 7, no. 9, pp. 923-926, 2012.

[68] M. Sengan, D. Veeramuthu, and A. Veerappan, "Photosynthesis of silver nanoparticles using Durio zibethinus aqueous extract and its application in catalytic reduction of nitroaromatics, degradation of hazardous dyes and selective colorimetric sensing of mercury ions," Materials Research Bulletin, vol. 100, pp. 386-393, 2018.

[69] G. A. Martínez-Castañón, N. Niño-Martínez, F. MartínezGutierrez, J. R. Martínez-Mendoza, and F. Ruiz, "Synthesis and antibacterial activity of silver nanoparticles with different sizes," Journal of Nanoparticle Research, vol. 10, no. 8, pp. 1343-1348, 2008.

[70] Z. Yi, X. Xu, X. Wu et al., "Silver nanoplates: controlled preparation, self-assembly, and applications in surface-enhanced Raman scattering," Applied Physics A, vol. 110, no. 2, pp. 335-342, 2013.

[71] S. S. Shankar, A. Rai, A. Ahmad, and M. Sastry, "Rapid synthesis of $\mathrm{Au}, \mathrm{Ag}$, and bimetallic Au core-Ag shell nanoparticles using neem (Azadirachta indica) leaf broth," Journal of Colloid and Interface Science, vol. 275, no. 2, pp. 496-502, 2004.

[72] K. Murugan, C. Raman, C. Panneerselvam et al., "Nano-insecticides for the control of human and crop pests," in Short Views on Insect Genomics and Proteomics, pp. 229-251, Springer, Cham, Switzerland, 2016.

[73] M. Govindarajan, M. Rajeswary, K. Veerakumar, U. Muthukumaran, S. L. Hoti, and G. Benelli, "Green synthesis and characterization of silver nanoparticles fabricated using Anisomeles indica: mosquitocidal potential against malaria, dengue and Japanese encephalitis vectors," Experimental Parasitology, vol. 161, pp. 40-47, 2016.

[74] M. Puchalski, P. Dąbrowski, W. Olejniczak, P. Krukowski, P. Kowalczyk, and K. Polański, "The study of silver nanoparticles by scanning electron microscopy, energy dispersive $\mathrm{X}$-ray analysis and scanning tunnelling microscopy," Materials Science-Poland, vol. 25, no. 2, pp. 473-478, 2007.

[75] J. Y. Song and B. S. Kim, "Rapid biological synthesis of silver nanoparticles using plant leaf extracts," Bioprocess and Biosystems Engineering, vol. 32, no. 1, pp. 79-84, 2009.

[76] S. Joseph and B. Mathew, "Microwave-assisted green synthesis of silver nanoparticles and the study on catalytic activity in the degradation of dyes," Journal of Molecular Liquids, vol. 204, pp. 184-191, 2015.

[77] J. Cheon and W. Park, "Green synthesis of silver nanoparticles stabilized with mussel-inspired protein and colorimetric sensing of lead (II) and copper (II) ions," International Journal of Molecular Sciences, vol. 17, no. 12, 2006.

[78] R. Kumar, S. M. Roopan, A. Prabhakarn, V. G. Khanna, and S. Chakroborty, "Agricultural waste Annona squamosa peel extract: biosynthesis of silver nanoparticles," Spectrochimica Acta Part A: Molecular and Biomolecular Spectroscopy, vol. 90, pp. 173-176, 2012.

[79] C. K. Balavigneswaran, T. Sujin Jeba Kumar, R. Moses Packiaraj, and S. Prakash, "Rapid detection of $\mathrm{Cr}(\mathrm{VI})$ by AgNPs probe produced by Anacardium occidentale fresh leaf 
extracts," Applied Nanoscience, vol. 4, no. 3, pp. 367-378, 2014.

[80] D. S. Sheny, J. Mathew, and D. Philip, "Phytosynthesis of Au, $\mathrm{Ag}$ and $\mathrm{Au}-\mathrm{Ag}$ bimetallic nanoparticles using aqueous extract and dried leaf of Anacardium occidentale," Spectrochimica Acta Part A: Molecular and Biomolecular Spectroscopy, vol. 79, no. 1, pp. 254-262, 2011.

[81] C. Picart, A. Schneider, O. Etienne et al., "Controlled degradability of polysaccharide multilayer films in vitro and in vivo," Advanced Functional Materials, vol. 15, no. 11, pp. 1771-1780, 2005.

[82] Y. N. Rao, D. Banerjee, A. Datta, S. K. Das, R. Guin, and A. Saha, "Gamma irradiation route to synthesis of highly redispersible natural polymer capped silver nanoparticles," Radiation Physics and Chemistry, vol. 79, no. 12, pp. 12401246, 2010.

[83] W. Hou and S. B. Cronin, "A review of surface plasmon resonance-enhanced photocatalysis," Advanced Functional Materials, vol. 23, no. 13, pp. 1612-1619, 2013.

[84] J. Pletz, F. Sánchez-Bayo, and H. A. Tennekes, "Dose-response analysis indicating time-dependent neurotoxicity caused by organic and inorganic mercury-Implications for toxic effects in the developing brain," Toxicology, vol. 347-349, pp. 1-5, 2016.

[85] G. V. Ramesh and T. P. Radhakrishnan, "A universal sensor for mercury (Hg, HgI, HgII) based on silver nanoparticleembedded polymer thin film," ACS Applied Materials \& Interfaces, vol. 3, no. 4, pp. 988-994, 2011.

[86] Y. Guo, Z. Wang, W. Qu, H. Shao, and X. Jiang, "Colorimetric detection of mercury, lead and copper ions simultaneously using protein-functionalized gold nanoparticles," Biosensors and Bioelectronics, vol. 26, no. 10, pp. 4064-4069, 2011.

[87] A. Bard, Standard Potentials in Aqueous Solution, Routledge, Abingdon, UK, 2017.

[88] L. Katsikas, M. Gutiérrez, and A. Henglein, "Bimetallic colloids: silver and mercury," The Journal of Physical Chemistry, vol. 100, no. 27, pp. 11203-11206, 1996.

[89] A. Fan, Y. Ling, C. Lau, and J. Lu, "Direct colorimetric visualization of mercury $\left(\mathrm{Hg}^{2+}\right)$ based on the formation of gold nanoparticles," Talanta, vol. 82, no. 2, pp. 687-692, 2010. 

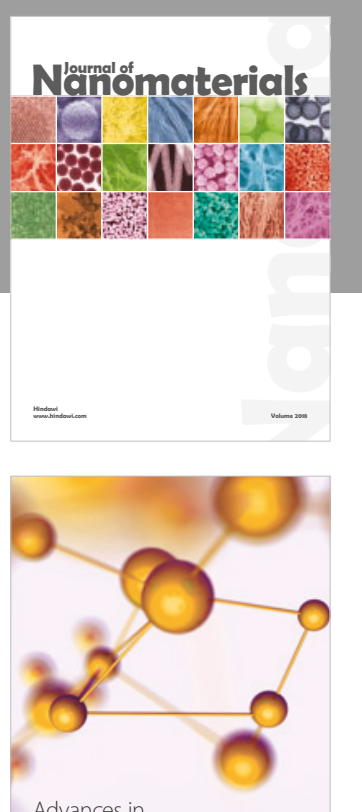

Physical Chemistry
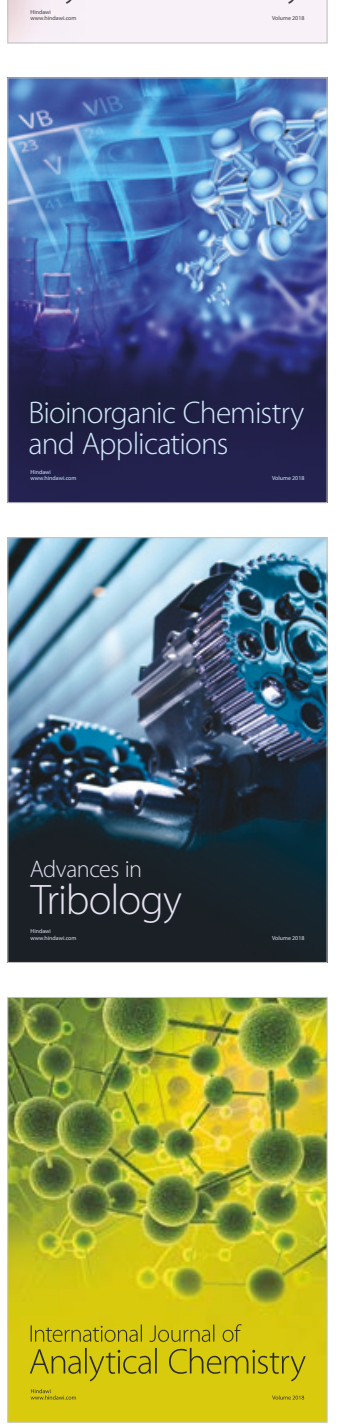

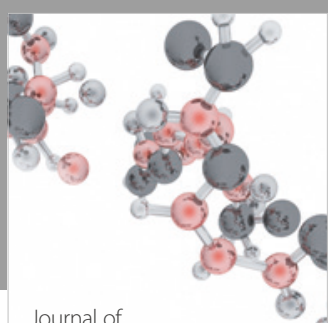

Analytical Methods

in Chemistry

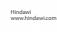

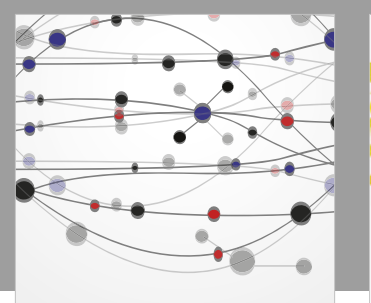

The Scientific World Journal

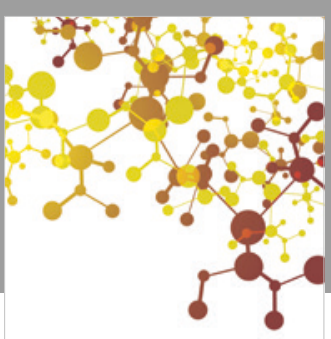

Journal of

Applied Chemistry
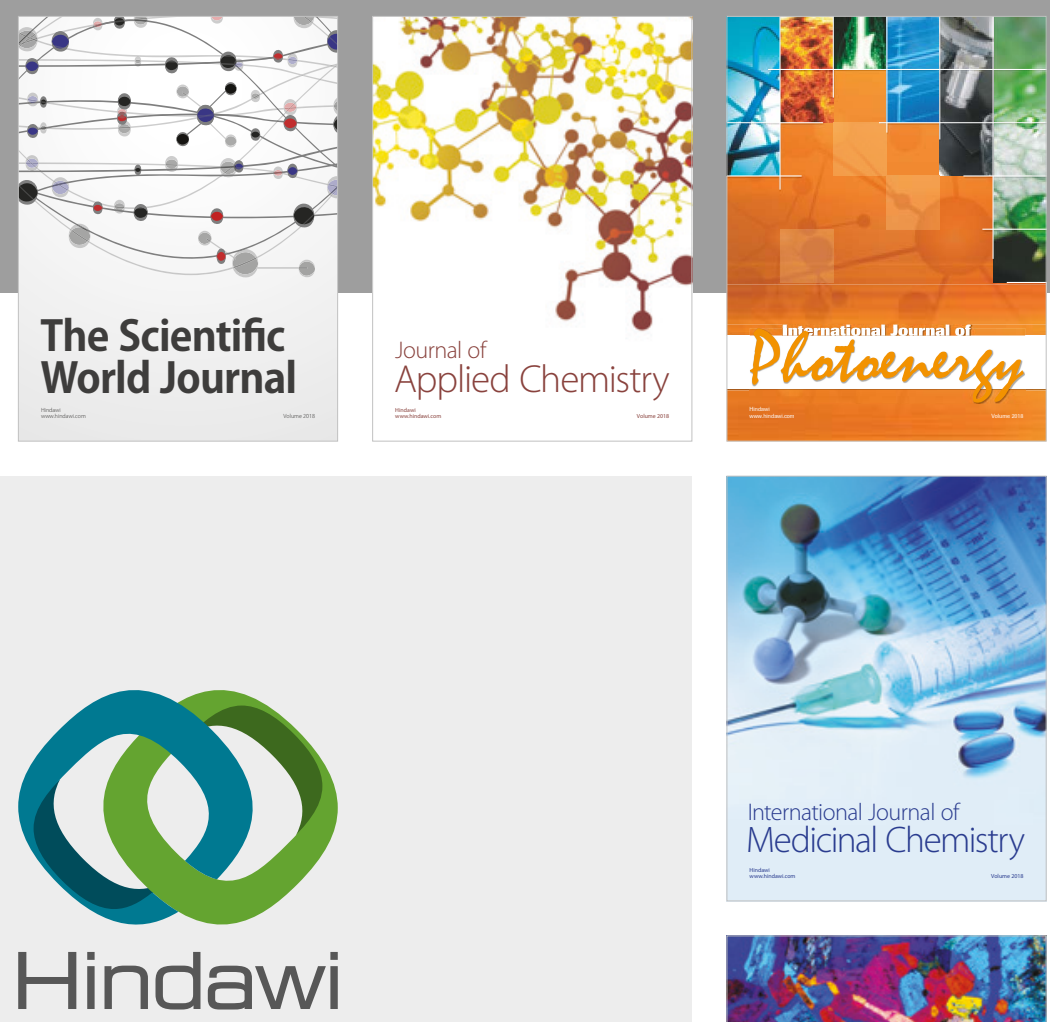

Submit your manuscripts at

www.hindawi.com
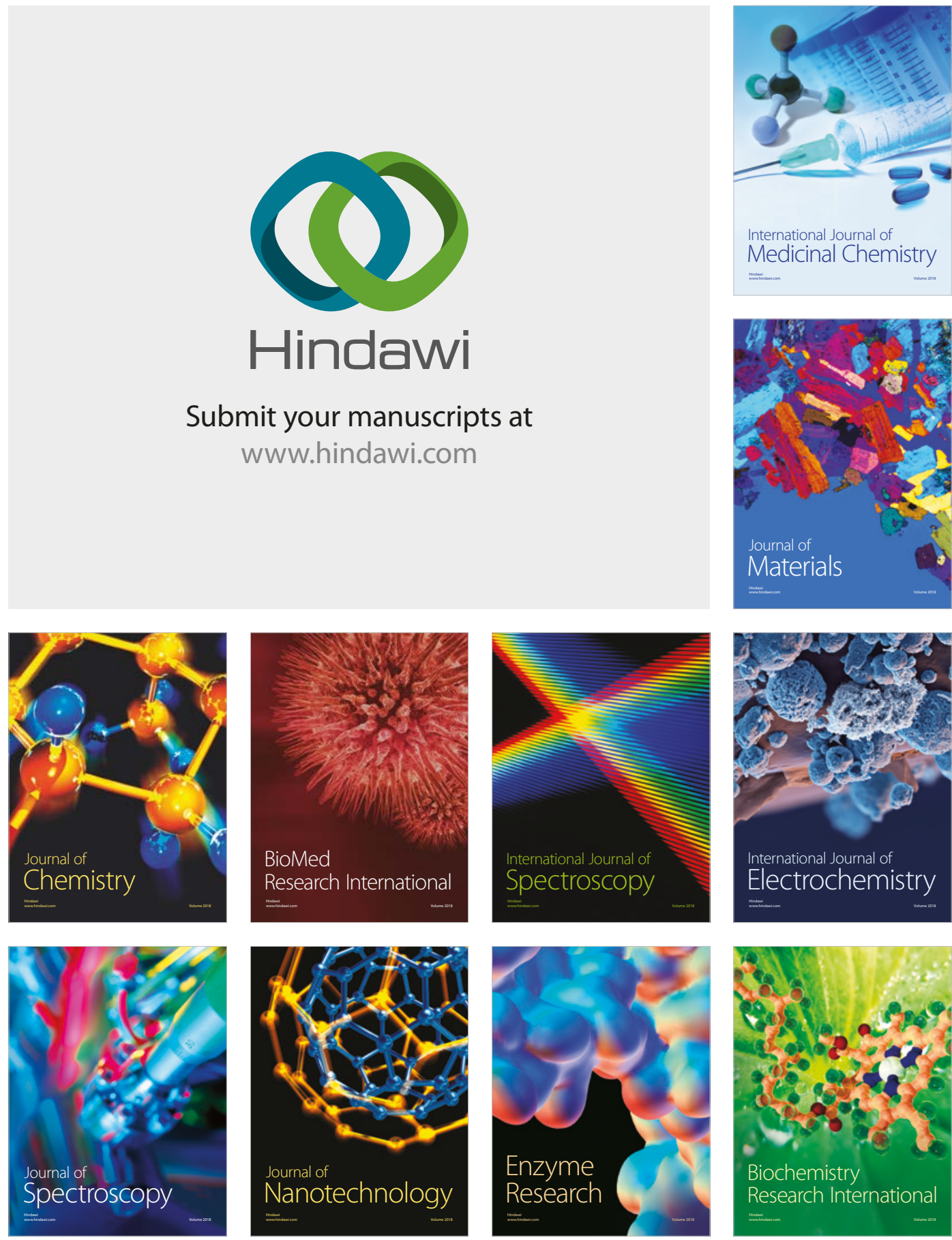
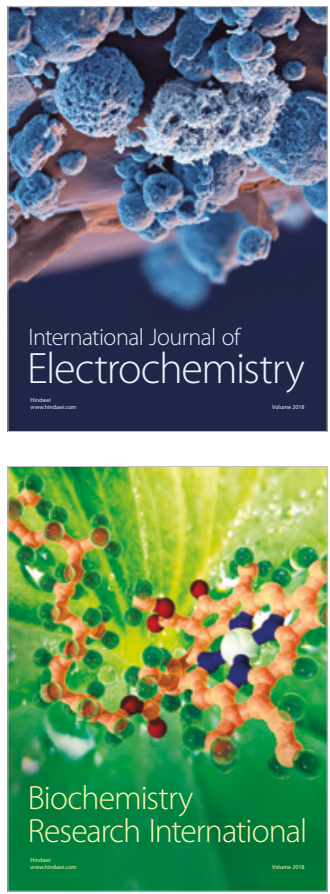